\title{
Metabolic Syndrome and Genotype 1 Virus C Compensated Liver Cirrhosis in the Era of Directly Acting Antiviral Therapy
}

\author{
Catalina Mihai, ${ }^{1,2}$ Bogdan Mihai, ${ }^{1,3,}$ Anca Trifan, ${ }^{1,2}$ Carol Stanciu, ${ }^{1,2}$ Liana Gheorghe, ${ }^{4}$ Mircea \\ Diculescu, ${ }^{4}$ Manuela Curescu, ${ }^{5}$ Ciprian Brisc, ${ }^{6}$ Adrian Goldis, ${ }^{7}$ Simona Bataga, ${ }^{8}$ Larisa Sandulescu, ${ }^{9}$
}

\author{
Ion Rogoveanu, ${ }^{9}$ Andrada Seicean,${ }^{10}$ and Cristina Cijevschi Prelipcean ${ }^{1,2}$ \\ ${ }^{1}$ University of Medicine and Pharmacy “Grigore T. Popa”, Iasi, Romania \\ ${ }^{2}$ Institute of Gastroenterology and Hepatology, “St. Spiridon” Emergency Hospital, Iasi, Romania \\ ${ }^{3}$ Center of Diabetes, Nutrition and Metabolic Diseases, “St. Spiridon” Emergency Hospital, Iasi, Romania \\ ${ }^{4}$ Digestive Diseases and Liver Transplantation Center, Fundeni Clinical Institute, Bucharest, Romania \\ ${ }^{5}$ University Hospital Infectious Diseases, Timisoara, Romania \\ ${ }^{6}$ Clinic of Gastroenterology and Hepatology, Oradea, Romania \\ ${ }^{7}$ Center Gastroenterology and Hepatology, University of Medicine and Pharmacy, Timisoara, Romania \\ ${ }^{8}$ Center of Gastroenterology, University of Medicine and Pharmacy, Tirgu Mures, Romania \\ ${ }^{9}$ Clinic of Gastroenterology and Hepatology, University of Medicine and Pharmacy, Craiova, Romania \\ 10 "Prof. dr. Octavian Fodor" Regional Institute of Gastroenterology and Hepatology, ClujNapoca, Romania \\ "Corresponding author: Bogdan Mihai, MD, PhD, Associate Professor, University of Medicine and Pharmacy “Grigore T. Popa”, Center of Diabetes, Nutrition and Metabolic \\ Diseases, “St. Spiridon” Emergency Hospital, Bd. Independentei, no 1, Iasi, 700 111, Romania. Tel: +4-0745328375, E-mail: bogdanmihai2003@yahoo.com
}

Received 2017 March 19; Accepted 2017 July 01.

\begin{abstract}
Objectives: The current study aimed at evaluating the association between metabolic syndrome (MeS) in patients with hepatitis $\mathrm{C}$ virus (HCV) liver cirrhosis (compensated, genotype, $1 \mathrm{~b}$ ) and changes after sustained viral response (SVR) following a 12-week therapy with paritaprevir, ritonavir, ombitasvir, dasabuvir, and ribavirin (PrOD+R).

Methods: The current multicenter retrospective study included 809 patients diagnosed with compensated HCV cirrhosis (child class A), all $1 \mathrm{~b}$ genotype treated for 12 weeks with direct acting antiviral agents - PrOD+R - regimen (according to the protocol practiced in Romania) and achieved SVR. The parameters of MeS (according to the definition of the International Diabetes Federation) were collected from medical records before and 12 weeks after the treatment. The results were collected in a central database and analyzed with SPSS 18.0. Statistical analysis used both descriptive and analytical methods with a significance level of 95\% (CI 95\%).

Results: Out of the 809 patients, 105 (13\%) demonstrated 3 out of the 5 criteria for MeS. Based on the MeS criteria, the commonest parameters were abnormal glycaemia (54.1\%), followed by visceral obesity (38.6\%), raised triglycerides (26.1\%), high blood pressure (12.1\%), and a low high-density lipoprotein (HDL)-cholesterol (4.6\%). The re-assessment of MeS parameters after SVR showed favourable changes, which were statistically significant: a siginficanttly lower serum triglyeride level $(182.32 \mathrm{vs} .153 .50 \mathrm{mg} / \mathrm{dL}, \mathrm{P}=$ 0.001), lower systolic arterial blood pressure (130.57 vs. $124.85 \mathrm{mmHg} ; \mathrm{P}=0.001)$, lower diastolic arterial blood pressure (80.26 vs. $78.42 \mathrm{mmHg} ; \mathrm{P}=0.001)$ and lower glyceamic levels (130.06 vs. $120.71 \mathrm{mg} / \mathrm{dL} ; \mathrm{P}=0.001)$, as well as a significant rise in HDL-cholesterol levels ( 48.61 vs. $50.50 \mathrm{mg} / \mathrm{dL} ; \mathrm{P}=0.003$ ). Abdominal circumference was the only parameter, which did not change after SVR. Following the changes sustained after SVR, $26.7 \%$ of the patients no longer fulfilled the minimum 3 criteria for MeS. No correlation was observed between the presence of MeS and the risk of severe adverse events, but it was noted that $37.5 \%$ of the patients who decompensated, $66.7 \%$ of the ones who developed hepatocarcinoma and $100 \%$ of the ones that died of abnormal glycaemic levels. Conclusions: Hyperglycemia, and not MeS, is associated with HCV compensated liver cirrhosis genotype 1b, and is a risk factor for severe adverse events. The attainment of SVR through PrOD+R regimen results in short-term improvements in MeS parameters.
\end{abstract}

Keywords: Hepatitis C Virus, Metabolic Syndrome, Hyperglycemia, Compensated Cirrhosis, Direct Acting Antiviral Agents, Sustained Viral Response

\section{Background}

Both the metabolic syndrome (MeS) and chronic infection with hepatitis $\mathrm{C}$ virus (HCV) are widely spread in the general population. Their association is not incidental, as there are common etiopathogenic links between the 2 conditions: insulin resistance, type 2 diabetes mellitus
(T2DM), and liver steatosis. Nevertheless, the published data are still controversial $(1,2)$. HCV induces a specific form of metabolic syndrome called "hepatitis C-associated dysmetabolic syndrome” (HCADS), which includes hyperuricemia, reversible hypocholesterolemia, insulin resistance, hypertension, and visceral obesity (3). There are many pathogenic mechanisms involved in the develop-

Copyright (c) 2017, Hepatitis Monthly. This is an open-access article distributed under the terms of the Creative Commons Attribution-NonCommercial 4.0 International License (http://creativecommons.org/licenses/by-nc/4.0/) which permits copy and redistribute the material just in noncommercial usages, provided the original work is properly cited. 
ment of hepatic insulin-resistance in patients with $\mathrm{HCV}$, both through a direct viral effect and through inflammatory cytokines: the inhibition of insulin receptor substrate (IRS), and the activation of suppressor of cytokine sing-align (SOCS) with inhibition of phosphatidylinositol 3 kinase-transducer, which has a key role in insulin metabolism (4). As far as the lipid metabolism is concerned, HCV relies on the host lipid metabolism to enter the hepatocytes and replicate, consequently impacting on the lipid metabolism itself (5). The hepatic accumulation of lipids is caused both by virus (viral steatosis in genotype 3 virus) and other associated metabolic factors in other genotypes (metabolic steatosis). They have multiple mechanisms: increased availability of lipogenic substrate, increased de novo lipogenesis, decreased oxidation of fatty substrates, and decreased export of fatty substrates from the hepatocyte into the bloodstream (3). Insulin-resistance and hepatic steatosis are the negative risk factors in HCV infection, leading to accelerated progression of hepatic fibrosis, risk of hepatocarcinoma, and in mortality through cardiovascular complications (6).

In the recent years, HCV therapy is revolutionized through the development of directly acting antiviral therapy (DAA), an efficient, quick, and well tolerated therapy with the potential to cure HCV infection. Whilst metabolic parameters were the negative prognostic risk factors in peginterferon and ribavirin therapy, they do not seem to affect the sustained viral response (SVR) in DAA. Genotype 3 virus (associated with hepatitis virus-induced steatosis) is an exception, as it is now the most difficult type to treat $(7,8)$. There is no consensus in this regard, with some data suggesting that certain metabolic parameters (for examples, the low levels of low density lipoprotein (LDL)cholesterol) prior to treatment have a negative impact on SVR even in DAA therapy (9).

The achievement of SVR following antiviral therapy with peginterferon and ribavirin reduces insulin resistance, lowers the incidence of T2DM, and reestablishes lipid homeostasis (8). The eradication of HCV with the new DAA regimen in almost all patients does not equate with a cure. The risk of liver disease progression, the development of hepatocarcinoma, and extra hepatic complications (T2DM and cardiovascular disease) remain even after achieving SVR (10). The impact of viral eradication on MeS parameters is currently not known well.

The current study aimed at evaluating the association of MeS in patients with HCV liver cirrhosis (compensated genotype $1 \mathrm{~b}$ ) and changes in MeS parameters after SVR, following a 12-week therapy with paritaprevir, ritonavir, ombitasvir, dasabuvir, and ribavirin (PrOD+R).

\section{Methods}

A multicenter retrospective study included 809 patients diagnosed with compensated HCV cirrhosis (child class A), all $1 \mathrm{~b}$ genotypetreated for 12 weeks with DAA (PrOD+R) regimen (according to the protocol practiced in Romania), and achieved SVR. The analysis used anonymous data obtained after patients agreed to directly acting antiviral therapy by written consent. Clinical characteristics and laboratory data were collected from medical records. The diagnosis of HCV liver cirrhosis was made through clinical, biological, and imaging parameters, as well as non-invasive methods (FibroMax) of assessing liver fibrosis. FibroMax is a non-invasive method of determining the activity, alcoholic and non-alcoholic steatosis, and liver fibrosis through an algorithm, which measures the following markers: $\alpha 2$-macroglobulin, haptoglobin, apolipoprotein A1, $\gamma$-glutamyltransferase, alanine and aspartate aminotransferase, total bilirubin, fasting glucose, cholesterol, and triglycerides. Treatment continued for 12 weeks from 01 December, 2015 to 20 June, 2016, with an undetectable viral load at 12 weeks from completion of therapy (SVR). Patients with decompensated liver cirrhosis, hepatocarcinoma, co-infections with hepatitis B or HIV, and chronic alcohol users prior to the treatment were excluded from the study.

During the physical examination, the following measurements were made using standard procedures: waist circumference, and systolic and diastolic blood pressure (SBP and DBP, respectively). Fasting plasma glucose (FPG), triglycerides (TG), and high-density lipoprotein (HDL)cholesterol were determined using enzymatic methods.

MeS was defined according to the definition of the international diabetes federation as fulfilling 3 of the 5 criteria: abdominal circumference $>90 \mathrm{~cm}$ in males and $>80$ $\mathrm{cm}$ in females, fasting plasma glucose $>100 \mathrm{mg} / \mathrm{dL}$ (or a diagnosis of T2DM), triglycerides $>150 \mathrm{mg} / \mathrm{dL}$ (or therapy with fibrates), HDL-cholesterol $<40 \mathrm{mg} / \mathrm{dL}$ in males and $<50 \mathrm{mg} / \mathrm{dL}$ in females (or hypolipemiant therapy), BP > $130 / 85 \mathrm{mmHg}$ (or treated arterial hypertension) (11).

All patients were assessed prior to starting DAA therapy and at the time of SVR(24 weeks after the commencement). The severe adverse events at SVR visit were also noted: liver decompensation (ascites, hepatoportal encephalopathy, and upper digestive bleeding), hepatocarcinoma, and death.

The results were collected in a central database and analyzed with SPSS18.0. Statistical analysis used both descriptive and analytical methods with a significance level of $95 \%$ (CI 95\%). The student t test was used to calculate significant differences between means and the F test (ANOVA) was used to compare median values in 3 or more groups with 
normal distributions. The $\mathrm{X}^{2}$ nonparametric test was used to compare 2 or more frequencies arising from the same population, used when expected events were excluded. The Kruskal-Wallis, non-parametric test was used to compare data from 3 or more frequencies.

\section{Results}

The current cohort study included 438 females (54.1\%) and 371 males (45.9\%), within the age range of 34 to 79 years and the mean age of $59.21 \pm 8.72$ years.

The abdominal circumference varied in males from 67 to $132 \mathrm{~cm}$, and in females from 58 to $163 \mathrm{~cm}$, with significant differences between the means of genders ( 90.02 vs. 81.52 $\mathrm{cm}, \mathrm{P}=0.001)$. Abdominal obesity was observed in $312 \mathrm{pa}-$ tients (38.56\%), with more commonality in females (45.4\%) compared with males (30.5\%).

Glycemic levels ranged from 61 to $310 \mathrm{mg} / \mathrm{dL}$, with no significant differences in the means between the genders (108.53 mg/dL males vs. $108.67 \mathrm{mg} / \mathrm{dL}$ females; $\mathrm{P}=0.953$ ). Glycemic levels consistent with a diagnosis of MeS were observed in 438 patients (54.14\%) with no significant differences between genders (54.4\% vs. 53.9\%; $\mathrm{P}=0.928$ ).

Serum triglycerides ranged from 38 to $610 \mathrm{mg} / \mathrm{dL}$, with a slightly higher mean in males (131.51 vs. $125.89 \mathrm{mg} / \mathrm{dL}$; P $=0.125$ ). The criteria of MeS were observed in 211 patients (26.08\%). There was no significant differences between genders (27.2\% vs. $25.1 \%$; $=0.548)$.

Only 37 patients (4.57\%) had HDL-cholesterol levels consistent with those of MeS. HDL-cholesterol in males ranged from 31 to $68 \mathrm{mg} / \mathrm{dL}$, and in females from 33 to $68 \mathrm{mg} / \mathrm{dL}$, with no significant mean differences between the genders ( 54.65 vs. $54.88 \mathrm{mg} / \mathrm{dL} ; \mathrm{P}=0.557$ ). In addition, $2.4 \%$ of males and $6.4 \%$ of females had values consistent with those of MeS, representing a significant statistical difference $(P=$ $0.007)$.

SBP ranged from 90 to $170 \mathrm{mmHg}$, whilst DBP ranged from 60 to $100 \mathrm{mmHg}$, with no significant mean differences between the genders (125.08 vs. $124.60 \mathrm{mmHg}$, P $=0.584$ and 75.22 vs. $76.24 \mathrm{mmHg}, \mathrm{P}=0.123$, respectively). High blood pressure or normal pressure in the context of antihypertensive therapy was observed in 98 patients (12.11\%) with no significant differences between males $(13.5 \%)$ and females $(11 \%)(\mathrm{P}=0.327)$.

The descriptive MeS parameters according to the gender are presented in Table 1.

Based on the MeS criteria, the commonest parameter was abnormal glycaemia (54.1\%), followed by visceral obesity (38.6\%), raised TG (26.1\%), high BP (12.1\%), and a low HDLcholesterol (4.6\%).

Out of the 809 patients, 105 (13\%) demonstrated 3 out of the 5 criteria for MeS. In the current study, $59 \%$ of the pa- tients were female with a female to male ratio of 1.4:1. Age ranged from 37 to 79 years with the mean age of 61 years close to that of the cohort study ( $59.75 \pm 8.28$ years), and the peak of frequency around 60 years. The mean age was lower in males ( 55.72 ) compared with females ( 62.55 years) $(\mathrm{P}=0.001)$.

The study data demonstrated the following results based on the diagnostic criteria for MeS:

- Five diagnostic criteria were present in 3 patients $(0.4 \%)$

- Four diagnostic criteria were present in 3.5\% of the patients as follows: 16 patients with abdominal obesity, $\uparrow$ TG, $\downarrow$ HDL, and $\uparrow$ FPG, 7 patients with abdominal obesity, $\uparrow$ TG, $\uparrow \mathrm{BP}$, and $\uparrow$ FPG, 5 patients with abdominal obesity, $\downarrow$ HDL, $\uparrow \mathrm{BP}$, and $\uparrow \mathrm{FPG}$, and 1 patient with $\uparrow \mathrm{TG}, \downarrow \mathrm{HDL}, \uparrow \mathrm{BP}$, and $\uparrow$ FPG;

- Three diagnostic criteria were present in 9.1\% of the patients: 37 patients with abdominal obesity, $\uparrow \mathrm{TG}$ and $\uparrow$ FPG, 6 patients with abdominal obesity, $\downarrow$ HDL and $\uparrow$ FPG; 13 patients with abdominal obesity, $\uparrow \mathrm{BP}$ and $\uparrow$ FPG, 3 patients with $\uparrow \mathrm{TG}, \uparrow \mathrm{BP}$, and $\uparrow \mathrm{FPG}, 4$ patients with abdominal obesity, $\uparrow \mathrm{TG}$ and $\uparrow \mathrm{BP}$, and 8 patients with abdominal obesity, $\uparrow \mathrm{TG}$ and $\uparrow \mathrm{BP}$.

The most frequent association in MeS was abdominal obesity, $\uparrow \mathrm{TG}$, and $\uparrow$ FPG (37 patients; $35.2 \%$ ).

The re-assessment of MeS parameters after SVR showed favourable changes which were statistically significant (Tabel 2): a siginficanttly lower serum triglyeride level (182.32 vs. $153.50 \mathrm{mg} / \mathrm{dL}, \mathrm{P}=0.001$ ), lower SBP (130.57 vs. $124.85 \mathrm{mmHg}$; $\mathrm{P}=0.001$ ), lower DBP ( 80.26 vs. $78.42 \mathrm{mmHg}$; $\mathrm{P}=0.001$ ), and lower glyceamic levels (130.06 vs. 120.71 $\mathrm{mg} / \mathrm{dL} ; \mathrm{P}=0.001$ ), as well as a significant rise in HDL cholesterol levels ( 48.61 vs. $50.50 \mathrm{mg} / \mathrm{dL} ; \mathrm{P}=0.003$ ). Abdominal circumference was the only parameter, which did not change after SVR (Table 2).

Following the changes sustained after SVR, $26.7 \%$ of the patients no longer fulfilled the minimum 3 criteria for MeS (Table 3). The most significant improvements from a frequency perspective were noted in the reduction of BP and triglyceride levels.

In the studied cohort, there were 23 severe adverse events (2.84\%): 8 decompensations of liver disease, 12 hepatocarcinomas, and 3 deaths. No correlation was found between the presence of MeS and the risk of severe adverse events (Table 4). Instead, it was noted that $37.5 \%$ of the patients who decompensated, $66.7 \%$ of the ones who developed hepatocarcinoma, and $100 \%$ of those that died had abnormal glycemic levels. 
Table 1. Descriptive Indicators of Metabolic Syndrome Parameters According to the Gender

\begin{tabular}{|c|c|c|c|c|c|c|c|c|}
\hline \multirow[t]{2}{*}{ Parameter } & \multirow[t]{2}{*}{ Gender } & \multirow[t]{2}{*}{$\mathbf{N}$} & \multirow[t]{2}{*}{ Mean \pm Std. Deviation } & \multirow[t]{2}{*}{ Std. Error } & \multicolumn{2}{|c|}{ 95\% Confidence Interval for Mean } & \multirow[t]{2}{*}{ Min } & \multirow[t]{2}{*}{$\operatorname{Max}$} \\
\hline & & & & & Lower Bound & Upper Bound & & \\
\hline \multirow{2}{*}{$\mathrm{AC}, \mathrm{cm}$} & Male & 371 & $90.02 \pm 9.43$ & 0.49 & 89.06 & 90.98 & 67 & 132 \\
\hline & Female & 438 & $81.52 \pm 10.62$ & 0.51 & 80.52 & 82.52 & 58 & 163 \\
\hline \multirow{2}{*}{ TG, mg/dL } & Male & 371 & $131.51 \pm 58.64$ & 3.04 & 125.52 & 137.49 & 38 & 610 \\
\hline & Female & 438 & $125.89 \pm 45.35$ & 2.17 & 121.63 & 130.15 & 40 & 410 \\
\hline \multirow{2}{*}{ HDL, mg/dL } & Male & 371 & $54.65 \pm 5.67$ & 0.29 & 54.07 & 55.23 & 31 & 68 \\
\hline & Female & 438 & $54.88 \pm 5.51$ & 0.26 & 54.37 & 55.40 & 33 & 68 \\
\hline \multirow{2}{*}{ SBP, mmHg } & Male & 371 & $125.08 \pm 12.30$ & 0.64 & 123.82 & 126.33 & 91 & 159 \\
\hline & Female & 438 & $124.60 \pm 12.43$ & 0.59 & 123.43 & 125.77 & 90 & 170 \\
\hline \multirow{2}{*}{ DBP, $\mathrm{mmHg}$} & Male & 371 & $75.22 \pm 9.49$ & 0.49 & 74.25 & 76.19 & 60 & 95 \\
\hline & Female & 438 & $76.24 \pm 9.11$ & 0.44 & 75.38 & 77.09 & 60 & 110 \\
\hline \multirow{2}{*}{ FPG, $\mathrm{mg} / \mathrm{dL}$} & Male & 371 & $108.53 \pm 30.44$ & 1.58 & 105.43 & 111.64 & 61 & 291 \\
\hline & Female & 438 & $108.67 \pm 33.18$ & 1.59 & 105.55 & 111.78 & 63 & 310 \\
\hline
\end{tabular}

Abbreviations: AC, abdominal circumference; DBP, diastolic blood pressure; FPG, fasting plasma glucose; HDL, high-density lipoproteins; SBP, systolic blood pressure; TG, triglycerides.

Table 2. Changes in Metabolic Syndrome Markers After the Achievement of Sustained Viral Response

\begin{tabular}{|c|c|c|c|c|c|}
\hline \multirow[t]{2}{*}{ Marker } & \multicolumn{2}{|c|}{ Initial } & \multicolumn{2}{|c|}{ SVR } & \multirow[t]{2}{*}{ P Value } \\
\hline & Mean \pm SD & Standard Error & Mean \pm SD & Standard Error & \\
\hline Triglycerides, mg/dL & $182.32 \pm 76.34$ & 7.45 & $153.50 \pm 63.38$ & 6.19 & 0.001 \\
\hline HDL, mg/dL & $48.61 \pm 8.86$ & 0.86 & $50.50 \pm 7.80$ & 0.76 & 0.003 \\
\hline SBP, mm Hg & $130.57 \pm 13.58$ & 1.33 & $124.85 \pm 12.97$ & 1.27 & 0.001 \\
\hline DBP, mm Hg & $80.26 \pm 8.83$ & 0.86 & $78.42 \pm 8.77$ & 0.86 & 0.001 \\
\hline Glycaemia, mg/dL & $130.06 \pm 42.44$ & 4.14 & $120.71 \pm 34.70$ & 3.39 & 0.001 \\
\hline
\end{tabular}

Abbreviations: DBP, diastolic blood pressure; SBP, systolic blood pressure; SVR, sustained viral response.

Table 3. Percentage of Changes in Metabolic Syndrome Parameters After Achieving a Sustained Viral Response

\begin{tabular}{lccc}
\hline MeS Criteria & Initial & SVR & PValue \\
\hline Abdominal obesity & $100(95.2)$ & $100(95.2)$ & 1.000 \\
$\uparrow$ Blood pressure & $42(40.0)$ & $23(21.9)$ & 0.001 \\
$\uparrow$ Glycaemia & $91(96.7)$ & $84(80.0)$ & 0.034 \\
$\downarrow$ HDL & $37(35.2)$ & $26(24.8)$ & 0.024 \\
$\uparrow$ Triglyerides & $79(75.2)$ & $55(52.4)$ & 0.001 \\
MeS & $105(100.0)$ & $77(73.3)$ & \\
\hline
\end{tabular}

Abbreviation: MeS, metabolic syndrome; high $(\uparrow)$ or low $(\downarrow)$ values according to MeS definition.

${ }^{\mathrm{a}}$ Values are expressed as No. (\%).

\section{Discussion}

Multiple definitions of MeS exist, but all include obesity, insulin resistance / hyperglycemia, dyslipidemia, and arterial hypertension as the inclusion criteria. MeS leads to a rise in mortality, especially as a result of cardiovascular causes (12). The hepatic manifestation of MeS is steatosis, in the context of non-alcoholic fatty liver disease (NAFLD). Similarly, HCV infection induces hepatic steatosis through direct mechanisms (valid especially in genotype 3 ) and is associated with multiple metabolic abnormalities: HCADS (3). In the current study, the prevalence of MeS was $13 \%$, with a female to male ratio of 1.4:1; lower than estimated in the general population of Romania 38.5\% (13).

In the published literature, the presence of MeS in patients with HCV varied, $12.4 \%$ in Europe and 35\% in the United States $(14,15)$. These differences are explained by the 
Table 4. Metabolic Syndrome and Severe Adverse Events ${ }^{\mathrm{a}}$

\begin{tabular}{|c|c|c|c|c|c|c|c|c|c|}
\hline \multirow[t]{2}{*}{ Adverse Events } & \multirow[t]{2}{*}{ No MeS $(N=704)$} & \multirow[t]{2}{*}{$\operatorname{MeS}(N=105)$} & \multicolumn{5}{|c|}{ Mes Criteria } & \multirow[t]{2}{*}{ Mes } & \multirow[t]{2}{*}{ PValue } \\
\hline & & & $\uparrow \mathrm{AC}$ & $\uparrow \mathbf{T G}$ & $\downarrow$ HDL & $\uparrow \mathrm{BP}$ & $\uparrow \mathrm{FPG}$ & & \\
\hline $\operatorname{LCD}(N=8)(1.0 \%)$ & $7(1.0)$ & $1(1.0)$ & $1(12.5)$ & $1(12.5)$ & $1(12.5)$ & $1(12.5)$ & $3(37.5)$ & $1(12.5)$ & 0.968 \\
\hline HCC $(\mathrm{N}=12)(1.5 \%)$ & $9(1.3)$ & $3(2.9)$ & $7(58.3)$ & $4(33.3)$ & $1(8.3)$ & $1(8.3)$ & $8(66.7)$ & $3(33.3)$ & 0.212 \\
\hline Death $(N=3)(0.4 \%)$ & $3(0.4)$ & $0(0.0)$ & $0(0.0)$ & $1(33.3)$ & $0(0.0)$ & $1(33.3)$ & $3(100)$ & $0(0.0)$ & 0.503 \\
\hline
\end{tabular}

Abbreviations: AC, abdominal circumference; BP, blood pressure; FPG, fasting plasma glucose; HCC, hepatocarcinoma; HDL, high-density lipoproteins; LCD, liver cirrhosis decompensation; MeS, metabolic syndrome; TG, triglycerides; high $(\uparrow)$ or low $(\downarrow)$ values according to Mes definition.

Values are expressed as No. (\%).

different definitions of MeS used, extremely different cohort studies on patients with HCV infection and variations in the prevalence of MeS in the populations investigated. Many authors consider that, despite the fact that insulin resistance is the common etiological link, the prevalence of MeS in HCV infection is similar to that of the general population (16). Consequently, in a study by Lonardo, the prevalence of MeS in patients with HCV was $4.1 \%$, similar to that of the control group and reduced compared with the prevalence in NAFLD (27.9\%) (17).

Visceral obesity is one of the features of HCDAS, observed in $38.6 \%$ of the studied patients. It is demonstrated that insulin-resistance has a hepatic origin, as well as a peripheral one, with a hypothesis stating that HCV could infect fatty tissue (18). The association of obesity-hyperglycemia-hypertriglyceridemia was the most frequent occurrence in MeS.

Abnormal glycaemia was observed in more than half of the patients (54.14\%), much higher than expected in the general Romanian population (In a study by Predatorr the prevalence of glycemic abnormalities (pre-diabetes or diabetes) in the general Romanian population was 28.1\%.) (19). More than 20 years ago, Allison et al., demonstrated that T2DM was more frequent in HCV liver cirrhosis compared with other etiologies (20). Currently, it is known that HCV infection is associated with insulin-resistance, T2DM, and liver steatosis (21). In a recent meta-analysis, DM is considered as the second most common extra-hepatic manifestation of HCV (after depression), found in 15\% of the patients (22). The high proportion of patients with raised glycemic values could be explained by the advanced stage of liver fibrosis in the cohort studies, knowing that in HCV infection, T2DM correlates with the degree of hepatic fibrosis (23).

The interaction of HCV with lipid metabolism is a complex one, which is incompletely understood. HCADS, in particular, features the associations of hepatic steatosis with those of hypocholesterolemia and reduced triglyceride levels (1). The virus enters the hepatocyte by binding to LDL receptors. The low levels of LDL are caused by geranylgeranyl-diphosphate in viral replication, which is a substrate for the synthesis of cholesterol. The high levels of LDL compete with LDL receptors and reduce viral replication, whilst the high levels of HDL aid the entry of the virus into the hepatocyte (24). In the hepatocyte, HCV interferes with the lipid metabolism of the host to replicate and assemble leading to hepatic steatosis. The main mechanisms through which HCV leads to accumulation of triglycerides in the hepatocyte are the activation of lipogenesis, its impact on mitochondrial lipid oxidation, the lowering of microsomal triglyceride transfer protein activity, and the reduced activity of peroxisome proliferator activating receptor (PPAR) (4). The release of the virus from hepatocytes occurs by means of the very low-density lipoprotein (VLDL) (25). In the studied group of patients, hypertriglyceridemia was found in $26.08 \%$ of patients, whilst low HDL was encountered in only $5 \%$ of the patients. It was explained by the particular features of lipid metabolism associated with HCV.

Whilst there are a number of controversies, some evidence may suggest an involvement of HCV in the development of cardiovascular complication, insulin resistance, hepatic steatosis, and T2DM as a common link (26). In the current study, hypertension was observed in $12.1 \%$ of the patients.

The current study showed that all MeS parameters with the exception of abdominal circumference had a significant improvement after SVR. The most significant improvements were noted in the reduction of BP and triglyceride levels. Consequently, almost one-third of the patients no longer featured the diagnostic criteria for MeS. In a recently published study including 119 patients, Yair-Sabag et al., demonstrated a reduction in the incidence of T2DM in patients with SVR following peginterferon and ribavirin treatment. The same study did not identify any significant changes in MeS parameters before or after the treatment between responders and non-responders (27).

A number of studies indicate that the eradication of HCV through interferon-based therapy leads to an improvement in insulin resistance and a reduction in the incidence of T2DM (28-30). The current study confirmed this significant drop in glycemic levels (both in terms of mean value and the percentage of patients with hyperglycemia) 
after SVR is attained using DAA therapy. Similar results are recently published using other treatment regimens $(9,31)$.

The reversibility of hypocholesterolemia, hypotriglyceridemia, and hepatic steatosis is demonstrated after the attainment of SVR in therapy regimens based on interferon (32-34). In the current study, a rise in HDL-cholesterol was noted and a drop in triglyceride levels after attainment of SVR in patients treated with PrOD+R. Similarly, Meissner et al., noted a drop in the triglyceride levels beginning in the 4 th week of therapy with sofosbuvir and ribavirin, a rise in LDL-cholesterol, but no changes in the total cholesterol levels or HDL-cholesterol (35). The changes in lipid metabolism, which quickly appear after viral clearance, highlight once again the direct effect of HCV in lipid homeostasis (35).

The effects of viral eradication on cardiovascular risk are controversial. In the current study, there was a significant reduction in mean blood pressure post SVR, as well as a lower proportion of patients with hypertension. Some suggest that the attainment of SVR leads to a rise in blood lipids and consequently an increase in cardiovascular risk (6). In the current study, the improvement of arterial blood pressure after SVRemphasized the direct link between HCV and cardiovascular complications.

Regarding the incidence of severe adverse events, there were no associations with MeS. Instead, the obtained data confirmed that glycemic abnormalities were the important risk factors for decompensation, hepatocarcinoma, and death in patients with HCV liver cirrhosis. The risk of decompensation in HCV cirrhosis is more frequent in patients with T2DM (36). T2DM is considered as a risk factor for the development of hepatocellular carcinoma even in patients with SVR following DAA (37).

The study was limited by its retrospective nature with the exclusion of patients with incomplete data regarding initial metabolic parameters and after SVR. Similarly, the short follow-up period (24 weeks) did not allow assessment regarding the improvement of MeS parameters and possible implications on the risk of T2DM, cardiovascular, and renal diseases on the long-term follow-up.

The strengths of the study included the large number of patients recruited and the relatively homogenous nature of the studied population (all having genotype $1 \mathrm{~b}$ and F4 fibrosis). According to the authors' best knowledge; it was the only study in the literature that showed the reversibility of MeS in almost one-third of HCV compensated liver cirrhosis genotype $1 \mathrm{~b}$ patients after achieving SVR by PrOD + R regimen.

\subsection{Conclusions}

The role of HCV in the complexity of metabolic abnormalities remains a highly interesting topic for future re- search. Patients with HCV liver cirrhosis (compensated genotype $1 \mathrm{~b}$ ) frequently display features of MeS (high glycaemia, visceral obesity), but not MeS itself. Glycemic abnormalities are associated with a higher risk of hepatic decompensation, hepatocarcinoma, and death. The attainment of SVR through PrOD+R led to the short-term improvements in MeS parameters and the disappearance of this diagnosis in almost one-third of the treated patients. The long-term effects on the evolution of MeS and cardiovascular consequences require future studies.

\section{Acknowledgments}

Rusu Iuliana Lidia, statistician, revised the statistical methods of the study.

\section{Footnote}

Financial Disclosure: Authors declared no financial disclosure.

\section{References}

1. Negro F.HCV infection and metabolic syndrome: which is the chicken and which is the egg? Gastroenterology. 2012;142(6):1288-92. doi: 10.1053/j.gastro.2011.12.063. [PubMed: 22537435].

2. Cheng YL, Wang YC, Lan KH, Huo TI, Huang YH, Su CW, et al. Antihepatitis $\mathrm{C}$ virus seropositivity is not associated with metabolic syndrome irrespective of age, gender and fibrosis. Ann Hepatol. 2015;14(2):181-9. [PubMed: 25671827].

3. Lonardo A, Adinolfi LE, Restivo L, Ballestri S, Romagnoli D, Baldelli E, et al. Pathogenesis and significance of hepatitis $C$ virus steatosis: an update on survival strategy of a successful pathogen. World J Gastroenterol. 2014;20(23):7089-103. doi: 10.3748/wjg.v20.i23.7089. [PubMed: 24966582].

4. Kralj D, Virovic Jukic L, Stojsavljevic S, Duvnjak M, Smolic M, Curcic IB. Hepatitis C Virus, Insulin Resistance, and Steatosis. J Clin Transl Hepatol. 2016;4(1):66-75. doi: 10.14218/JCTH.2015.00051. [PubMed: 27047774].

5. Afzal MS, Zaidi NU, Dubuisson J, Rouille Y. Hepatitis C virus capsid protein and intracellular lipids interplay and its association with hepatic steatosis. Hepat Mon. 2014;14(8):e17812. doi: 10.5812/hepatmon.17812. [PubMed: 25237371].

6. Wong RJ, Gish RG. Metabolic Manifestations and Complications Associated With Chronic Hepatitis C Virus Infection. Gastroenterol Hepatol (NY). 2016;12(5):293-9. [PubMed: 27499712]

7. Rafi H, Kabbaj N, Salihoun M, Amrani L, Acharki M, Guedira M, et al. Influence of steatosis on progression of fibrosis and virological response in chronic hepatitis C cases. Arab J Gastroenterol. 2011;12(3):1368. doi: 10.1016/j.ajg.2011.07.003. [PubMed: 22055591].

8. Lim T. Metabolic syndrome in chronic hepatitis $C$ infection: does it still matter in the era of directly acting antiviral therapy? Hepat Med. 2014;6:113-8. doi: 10.2147/HMER.S60083. [PubMed: 25506251].

9. Moucari R, Forestier N, Larrey D, Guyader D, Couzigou P, Benhamou Y, et al. Danoprevir, an HCV NS3/4A protease inhibitor, improves insulin sensitivity in patients with genotype 1 chronic hepatitis C. Gut. 2010;59(12):1694-8. doi: 10.1136/gut.2010.219089. [PubMed: 20861007]. 
10. van der Meer AJ, Feld JJ, Hofer H, Almasio PL, Calvaruso V, FernandezRodriguez CM, et al. Risk of cirrhosis-related complications in patients with advanced fibrosis following hepatitis $C$ virus eradication J Hepatol. 2017;66(3):485-93. doi: 10.1016/j.jhep.2016.10.017. [PubMed: 27780714].

11. Alberti KG, Zimmet P, Shaw J, I. D. F. Epidemiology Task Force Consensus Group. The metabolic syndrome-a new worldwide definition. Lancet. 2005;366(9491):1059-62. doi: 10.1016/S0140-6736(05)67402-8. [PubMed: 16182882].

12. Sundstrom J, Riserus U, Byberg L, Zethelius B, Lithell H, Lind L. Clinical value of the metabolic syndrome for long term prediction of total and cardiovascular mortality: prospective, population based cohort study. BMJ. 2006;332(7546):878-82. doi: 10.1136/bmj.38766.624097.1F. [PubMed: 16510492].

13. Popa S, Mota M, Popa A, Mota E, Serafinceanu C, Guja C, et al. Prevalence of overweight/obesity, abdominal obesity and metabolic syndrome and atypical cardiometabolic phenotypes in the adult Romanian population: PREDATORR study. J Endocrinol Invest. 2016;39(9):1045-53. doi: 10.1007/s40618-016-0470-4. [PubMed 27126310].

14. Serste T, Nkuize M, Moucari R, Van Gossum M, Reynders M, Scheen R, et al. Metabolic disorders associated with chronic hepatitis C: impact of genotype and ethnicity. Liver Int. 2010;30(8):1131-6. doi:10.1111/j.14783231.2010.02291.x. [PubMed: 20536721].

15. Banks DE, Bogler Y, Bhuket T, Liu B, Wong RJ. Significant disparities in risks of diabetes mellitus and metabolic syndrome among chronic hepatitis C virus patients in the U.S. Diabetes Metab Syndr. 2016 doi: 10.1016/j.dsx.2016.12.025. [PubMed: 27989517].

16. Adinolfi LE, Rinaldi L, Guerrera B, Restivo L, Marrone A, Giordano M, et al. NAFLD and NASH in HCV Infection: Prevalence and Significance in Hepatic and Extrahepatic Manifestations. Int J Mol Sci. 2016;17(6) doi: 10.3390/ijms17060803. [PubMed: 27231906].

17. Lonardo A, Ballestri S, Adinolfi LE, Violi E, Carulli L, Lombardini S, et al. Hepatitis C virus-infected patients are 'spared' from the metabolic syndrome but not from insulin resistance. A comparative study of nonalcoholic fatty liver disease and hepatitis $\mathrm{C}$ virus-related steatosis. Can J Gastroenterol. 2009;23(4):273-8. [PubMed: 19373421]

18. Ballestri S, Nascimbeni F, Romagnoli D, Baldelli E, Targher G, Lonardo A. Type 2 Diabetes in Non-Alcoholic Fatty Liver Disease and Hepatitis C Virus Infection-Liver: The "Musketeer" in the Spotlight. Int J Mol Sci. 2016;17(3):355. doi:10.3390/ijms17030355. [PubMed: 27005620].

19. Mota M, Popa SG, Mota E, Mitrea A, Catrinoiu D, Cheta DM, et al. Prevalence of diabetes mellitus and prediabetes in the adult Romanian population: PREDATORR study. J Diabetes. 2016;8(3):336-44. doi: 10.1111/1753-0407.12297. [PubMed: 25850521].

20. Allison ME, Wreghitt T, Palmer CR, Alexander GJ. Evidence for a link between hepatitis $C$ virus infection and diabetes mellitus in a cirrhotic population. J Hepatol. 1994;21(6):1135-9. [PubMed: 7699240].

21. Safi SZ, Shah H, Siok Yan GO, Qvist R. Insulin resistance provides the connection between hepatitis $\mathrm{C}$ virus and diabetes. Hepat Mon 2015;15(1):e23941. doi: 10.5812/hepatmon.23941. [PubMed: 25741369].

22. Younossi Z, Park H, Henry L, Adeyemi A, Stepanova M. Extrahepatic Manifestations of Hepatitis C: A Meta-analysis of Prevalence, Quality of Life, and Economic Burden. Gastroenterology. 2016;150(7):1599-608. doi: 10.1053/j.gastro.2016.02.039. [PubMed: 26924097].

23. Romero-Gomez M, Fernandez-Rodriguez CM, Andrade RJ, Diago M, Alonso S, Planas R, et al. Effect of sustained virological response to treatment on the incidence of abnormal glucose values in chronic hepatitis C. J Hepatol. 2008;48(5):721-7. doi: 10.1016/j.jhep.2007.11.022. [PubMed: 18308416].

24. Gopal K, Johnson TC, Gopal S, Walfish A, Bang CT, Suwandhi P, et al. Correlation between beta-lipoprotein levels and outcome of hepatitis C treatment. Hepatology. 2006;44(2):335-40. doi: 10.1002/hep.21261. [PubMed: 16871569].

25. Zhu YZ, Qian XI, Zhao P, Qi ZT. How hepatitis C virus invades hepatocytes: the mystery of viral entry. World $J$ Gastroenterol. 2014;20(13):3457-67. doi: 10.3748/wjg.v20.i13.3457. [PubMed: 24707128].

26. Lonardo A, Ballestri S, Guaraldi G, Nascimbeni F, Romagnoli D, Zona $\mathrm{S}$, et al. Fatty liver is associated with an increased risk of diabetes and cardiovascular disease - Evidence from three different disease models: NAFLD, HCV and HIV. World J Gastroenterol. 2016;22(44):9674-93. doi: 10.3748/wjg.v22.i44.9674. [PubMed: 27956792].

27. Yair-Sabag S, Nussinson E, Ben-Assuli O, Shibli F, Shahbari A, Zelber-Sagi S. Retrospective study of the associations between hepatitis C virus infection and metabolic factors. World J Hepatol. 2016;8(30):1269-78. doi: 10.4254/wjh.v8.i30.1269. [PubMed: 27843537].

28. Delgado-Borrego A, Jordan SH, Negre B, Healey D, Lin W, Kamegaya $\mathrm{Y}$, et al. Reduction of insulin resistance with effective clearance of hepatitis C infection: results from the HALT-C trial. Clin Gastroenterol Hepatol. 2010;8(5):458-62. doi: 10.1016/j.cgh.2010.01.022. [PubMed: 20156586].

29. Thompson AJ, Patel K, Chuang WL, Lawitz EJ, Rodriguez-Torres M, Rustgi VK, et al. Viral clearance is associated with improved insulin resistance in genotype 1 chronic hepatitis $C$ but not genotype 2/3. Gut. 2012;61(1):128-34. doi: 10.1136/gut.2010.236158. [PubMed: 21873466].

30. Zhang W, Rao HY, Feng B, Liu F, Wei L. Effects of interferonalpha treatment on the incidence of hyperglycemia in chronic hepatitis C patients: a systematic review and meta-analysis. PLoS One. 2012;7(6):e39272. doi: 10.1371/journal.pone.0039272. [PubMed: 22768067].

31. Pavone P, Tieghi T, d'Ettorre G, Lichtner M, Marocco R, Mezzaroma $\mathrm{I}$, et al. Rapid decline of fasting glucose in HCV diabetic patients treated with direct-acting antiviral agents. Clin Microbiol Infect. 2016;22(5):462 e1-3. doi: 10.1016/j.cmi.2015.12.030. [PubMed: 26812446].

32. Fernandez-Rodriguez CM, Lopez-Serrano P, Alonso S, Gutierrez ML, Lledo JL, Perez-Calle JL, et al. Long-term reversal of hypocholesterolaemia in patients with chronic hepatitis $\mathrm{C}$ is related to sustained viral response and viral genotype. Aliment Pharmacol Ther. 2006;24(3):507-12. doi: 10.1111/j.1365-2036.2006.03000.x. [PubMed: 16886916].

33. Kuo $\mathrm{YH}$, Chuang TW, Hung $\mathrm{CH}$, Chen $\mathrm{CH}$, Wang $\mathrm{JH}$, Hu TH, et al. Reversal of hypolipidemia in chronic hepatitis $\mathrm{C}$ patients after successful antiviral therapy. J Formos Med Assoc. 2011;110(6):363-71. doi: 10.1016/S0929-6646(11)60054-5. [PubMed: 21741004].

34. Negro F. Mechanisms and significance of liver steatosis in hepatitis $C$ virus infection. World J Gastroenterol. 2006;12(42):6756-65. [PubMed: 17106922].

35. Meissner EG, Lee YJ, Osinusi A, Sims Z, Qin J, Sturdevant D, et al. Effect of sofosbuvir and ribavirin treatment on peripheral and hepatic lipid metabolism in chronic hepatitis C virus, genotype 1-infected patients. Hepatology. 2015;61(3):790-801. doi: 10.1002/hep.27424. [PubMed: 25203718].

36. Huang YW, Yang SS, Fu SC, Wang TC, Hsu CK, Chen DS, et al. Increased risk of cirrhosis and its decompensation in chronic hepatitis $\mathrm{C}$ patients with new-onset diabetes: a nationwide cohort study. Hepatology. 2014;60(3):807-14. doi: 10.1002/hep.27212. [PubMed: 24919583].

37. El-Serag HB, Kanwal F, Richardson P, Kramer J. Risk of hepatocellular carcinoma after sustained virological response in Veterans with hepatitis C virus infection. Hepatology. 2016;64(1):130-7. doi: 10.1002/hep.28535. [PubMed: 26946190]. 